\title{
Article \\ Role of the Mn-Catalase in Aerobic Growth of Lactobacillus plantarum ATCC 14431
}

\author{
Trent Peacock ${ }^{1}$ (D) and Hosni M. Hassan ${ }^{1,2, *(D)}$ \\ 1 Department of Microbiology, North Carolina State University, Raleigh, NC 27695-7615, USA; \\ tp1230@msstate.edu \\ 2 Prestage Department of Poultry Science, North Carolina State University, Raleigh, NC 27695-7608, USA \\ * Correspondence: hmhassan@ncsu.edu
}

check for

updates

Citation: Peacock, T.; Hassan, H.M. Role of the Mn-Catalase in Aerobic Growth of Lactobacillus plantarum ATCC 14431. Appl. Microbiol. 2021, 1, 615-625. https://doi.org/10.3390/ applmicrobiol1030040

Academic Editor: Philippe Guerre

Received: 10 November 2021 Accepted: 13 December 2021 Published: 18 December 2021

Publisher's Note: MDPI stays neutral with regard to jurisdictional claims in published maps and institutional affiliations.

Copyright: (c) 2021 by the authors. Licensee MDPI, Basel, Switzerland. This article is an open access article distributed under the terms and conditions of the Creative Commons Attribution (CC BY) license (https:// creativecommons.org/licenses/by/ $4.0 /)$.

\begin{abstract}
Lactobacilli are Gram-positive aerotolerant organisms that comprise the largest genus of Lactic Acid Bacteria (LAB). Most lactobacilli are devoid of the antioxidant enzymes, superoxide dismutases, and catalases, required for protection against superoxide radicals and hydrogen peroxide $\left(\mathrm{H}_{2} \mathrm{O}_{2}\right)$, respectively. However, some lactobacilli can accumulate millimolar concentrations of intracellular manganese and spare the need for superoxide dismutase, while others possess non-heme catalases. L. plantarum is associated with plant materials and plays an important role in fermented foods and gut microbiomes. Therefore, understanding the effects of the environment on the growth and survival of this organism is essential for its success in relevant industrial applications. In this report, we investigated the physiological role of Mn-catalase (MnKat) in Lactobacillus plantarum ATCC 14431. To this end, we compared the physiological and morphological properties of a $\Delta M n k a t$ mutant strain and its isogenic parental strain L. plantarum ATCC 14431. Our data showed that the MnKat is critical for the growth of L. plantarum ATCC 14431 in the presence of oxygen and resistance to $\mathrm{H}_{2} \mathrm{O}_{2}$. The aerobic growth of the mutant in presence or absence of $\mathrm{H}_{2} \mathrm{O}_{2}$ was improved in the Mn-rich medium (APT) as compared to the growth in MRS medium. Furthermore, under aerobic conditions the mutant strain possessed atypical cellular morphology (i.e., shorter, and fatter). In conclusion, the MnKat of L. plantarum ATCC 14431 is important for aerobic growth, protection against $\mathrm{H}_{2} \mathrm{O}_{2}$, and maintenance of the rod-shaped cell morphology under aerobic conditions.
\end{abstract}

Keywords: L. plantarum; Mn-catalase; hydrogen peroxide; oxidative stress; cell morphology

\section{Introduction}

Lactic acid bacteria (LAB) include a diverse group of microaerophilic, Gram-positive organisms that are generally regarded as catalase negative. Lactobacilli comprise the largest genus of the LAB group and occupy habitats ranging from foodstuffs to the microbiomes of humans and animals. In the presence of oxygen, lactobacilli generate reactive oxygen species (ROS) (i.e., superoxide radicals $\left(\mathrm{O}_{2}{ }^{-}\right)$, hydrogen peroxide $\left(\mathrm{H}_{2} \mathrm{O}_{2}\right)$, and hydroxyl radicals $(\mathrm{HO} \bullet))$. Indeed, in presence of oxygen, they can accumulate up to millimolar concentrations of $\mathrm{H}_{2} \mathrm{O}_{2}$ [1-6]. Therefore, mechanisms to combat the toxicity of $\mathrm{ROS}$ in $\mathrm{LAB}$ are essential for their aerobic survival. Indeed, understanding the mechanisms for combating oxidative stress in these economically important organisms is a critical element in maximizing their role in fermented foods, as well as in human and animal microbiome/health.

Some strains of LAB accumulate high concentrations of intracellular manganese (i.e., $\mathrm{mM}$ levels) and use it for non-enzymatic detoxification of superoxide radicals, $\mathrm{O}_{2}^{-}[1,7]$. On the other hand, the presence of antioxidant enzymes, i.e., manganese superoxide dismutases (MnSODs), heme-catalases, and manganese catalases, have been identified in a few selected species of LAB [8-23]. In general, lactic acid bacteria are unable to synthesize heme [24]. Therefore, the presence of a non-heme catalase, i.e., Mn-catalase (MnKat), in Lactobacillus plantarum ATCC 14431 represents an alternative mechanism 
for removing $\mathrm{H}_{2} \mathrm{O}_{2}$ in an organism that cannot synthesize heme or acquire it from the environment. Genes encoding Mn-catalase (Mnkat) from L. plantarum and L. casei have been cloned and heterologously expressed in Escherichia coli and L. bulgaricus [25,26]. Furthermore, the crystal structure and chemical properties of L. plantarum MnKat has been determined $[27,28]$.

Previous studies used chemicals to inhibit MnKat or compared non-isogenic strains to demonstrate the role of MnKat in protecting L. plantarum against $\mathrm{H}_{2} \mathrm{O}_{2}$ toxicity $[18,29]$. Recently, our group constructed a $\triangle M n k a t$ mutant in L. plantarum ATCC 14431 [30]. In the present study, we used the wildtype strain L. plantarum ATCC 14431 and its isogenic $\triangle M n k a t$ mutant strain to demonstrate the role of MnKat in protecting L. plantarum ATCC 14431 against $\mathrm{H}_{2} \mathrm{O}_{2}$, growth in presence of oxygen, and unexpectedly discovered its role in cellular morphology.

\section{Materials and Methods}

\subsection{Bacterial Strains, Media, and Growth Measurements}

L. plantarum, ATCC 14431 (NC1542) and its isogenic $\Delta$ Mnkat strain (NC 1543) (30) were cultured at $37^{\circ} \mathrm{C}$ in de Man Rogosa and Sharpe medium (MRS) or in APT medium (Becton-Dickinson). The MRS medium contained $220 \mu \mathrm{M}$ of $\mathrm{Mn}^{2+}$ while the APT contained $710 \mu \mathrm{M}$ of $\mathrm{Mn}^{2+}$.

When required, erythromycin $(\mathrm{Em}, 5 \mu \mathrm{g} / \mathrm{mL})$ was added to the cultures of the MnKat mutant. L. plantarum cultures were grown at $37^{\circ} \mathrm{C}$. Rotary shaker (New Brunswick, NJ, USA), (135 rpm), static incubator (Fisher Scientific, Waltham, MA, USA), or in a Coy anaerobic chamber (Coy Labs, Grass Lake, MI, USA) were used for oxic, static, or anoxic growth conditions, respectively. In all growth experiments, the liquid: flask ratio was 1:5. Growth was determined by measuring changes in optical density as a function of time at $600 \mathrm{~nm}\left(\mathrm{OD}_{600}\right)$ using a Kontron (Uvikon 810) spectrophotometer (Poway, CA, USA). Specific growth rates $\left(\mu_{\max } \cdot \mathrm{h}^{-1}\right)$ were calculated by linear regression from the rate of change of cell density from the expression: $\ln X / X_{0}=\mu_{\max }\left(t-t_{0}\right)$; where $X_{0}$ and $X$ are the cell densities at times $t_{0}$ and $t$, respectively.

\subsection{Chemicals and Enzymes}

$\mathrm{N}, \mathrm{N}^{\prime}$-tetramethylenediamine (TEMED), Lysozyme, 3,3'-diaminobenzidine, antibiotics, and horseradish peroxidase were purchased from Sigma-Aldrich (St. Louis, MO, USA). All other chemicals (i.e., hydrogen peroxide and bacteriological media) were purchased from Fisher Scientific (Pittsburgh, PA, USA).

\subsection{Preparation of Cell-Free Extracts (CFEs)}

Cultures of the L. plantarum strains were grown under aerobic conditions with shaking at $135 \mathrm{rpm}$ and $37{ }^{\circ} \mathrm{C}$. Cells were harvested, in the exponential growth phase, by centrifugation at $3000 \times g$ for $20 \mathrm{~min}$. Pellets were washed three times in an equal volume of phosphate-EDTA buffer (50 mM phosphate, $0.1 \mathrm{mM}$ EDTA buffer, $\mathrm{pH} 7.8$ ). After the final wash, the resulting pellet was suspended in phosphate-DTA buffer containing $1 \mathrm{mM}$ phenylmethanesulfonyl fluoride (PMSF), at 1/40th the original culture volume. This suspension was then transferred to a $2 \mathrm{~mL}$ gasket sealed screw cap tube containing $\sim \mathrm{g}$ of $0.2 \mathrm{~mm}$ silica beads (BioSpec, Inc., Bartlesville, OK, USA); for cellular disruption a MiniBeadBeater-8 (BioSpec, Inc., Bartlesville, OK, USA) was used. Cell/beads suspensions were homogenized for $10 \times 1$ min cycles with 3 min rest on ice in between each cycle to prevent sample overheating and protein denaturation. Following the final homogenization, cellular debris was precipitated by centrifugation at $20,000 \times g$ and $4{ }^{\circ} \mathrm{C}$ for $30 \mathrm{~min}$. The supernatant was transferred to 6000-8000 MW Cut-Off dialysis tubing, and dialyzed against two changes of phosphate-EDTA buffer at $4{ }^{\circ} \mathrm{C}$ for $24 \mathrm{~h}$. 


\subsection{Biochemical Assays}

Total protein concentration in CFEs was determined using the Bradford method [31], with bovine serum albumin (BSA) serving as the standard. Zymograms for catalase activity gels were performed using $10 \%$ non-denaturing native PAGE gels, and the staining method of Clare et al. [32]. A screening for catalase activity was performed by smearing a portion of a colony on a microscope slide followed by adding a drop of $3 \% \mathrm{H}_{2} \mathrm{O}_{2}$ and observing the presence or absence of $\mathrm{O}_{2}$ bubble formation. Catalase activity in CFEs was determined according to Beer's method based on a decrease in absorbance at $240 \mathrm{~nm}$ using an UVIKon810 dual-beam spectrophotometer [33]. Catalase was expressed as specific activity (U/mg protein). All experiments were performed in biological triplicate. The specific activity replicates were averaged and plotted as histograms with SE bars based on small sample size standard deviation using GraphPad Prism 4 for Macintosh (GraphPad Software, San Diego, CA, USA).

For comparing the biochemical profiles of wild-type (NC1542) and mutant (NC1543) strains, API 20E ${ }^{\mathrm{O}}$ (bioMérieux SA, Marcy 1"Etoile, France) strips were used according to manufacturer's specifications.

\subsection{Western Blotting}

Cell-free extracts (5-10 $\mu \mathrm{g}$ protein) were separated on a 10\% SDS-PAGE gel using Bio-Rad Mini-Protean II electrophoresis system (Bio-Rad, Inc., Hercules, CA, USA). Electrophoretically separated proteins were then electroblotted to a $0.45 \mu \mathrm{m}$ nitrocellulose membrane (Schleicher and Schüll, Dassel, Germany) using the Invitrogen XCell II blot module (Invitrogen, Corp., Carlsbad, CA, USA). Verification of complete transfer of protein bands was performed using Amido Black staining (Bio-Rad, Hercules, CA) of the membrane, per the manufacturer's instruction.

Membranes were then blocked for $1 \mathrm{~h}$ in blocking buffer [5\% (wt./vol) non-fat milk (Carnation) solubilized in PBS-T (phosphate buffered saline containing 0.1\% Tween 20, $\mathrm{pH}$ 7.0)]. Monoclonal antibodies, specific for MnKat (Gift from J.W. Whittaker, Oregon Health Sciences University, Portland, OR, USA), were added to fresh blocking buffer at a 1:10,000 dilution and incubated with the membrane for $2 \mathrm{~h}$. Membranes were then washed $3 \times 15$ min in blocking buffer after which fresh blocking buffer containing 1:10,000 goat anti-rabbit conjugated horseradish peroxidase antiserum was added to the membranes and incubated for additional $2 \mathrm{~h}$. Lastly, the membranes were washed in fresh blocking buffer $1 \times 15 \mathrm{~min}$ followed by another wash in PBS-T for $2 \times 15 \mathrm{~min}$. The signal was detected by incubating the membranes in an equal volume mixture of Western Lightning Chemiluminescence Reagent Plus substrates (Perkinelmer, Waltham, MA, USA) for 1 min followed by a 15-30 sec exposure to Kodak BioMax Light film (PerkinElmer, Waltham, MA, USA). Experiments were performed in biological triplicate.

\subsection{Effects of $\mathrm{H}_{2} \mathrm{O}_{2}$ on Growth $\left(\mathrm{OD}_{600 \mathrm{~nm}}\right)$}

These studies were performed in 96-well microtiterplates (NUNC-96F, ThermoFisher Scientific, Rochester, NY, USA). Each well contained $100 \mu \mathrm{L}$ aliquots of fresh MRS or APT media with or without $1 \mathrm{mM} \mathrm{H}_{2} \mathrm{O}_{2}$, and were inoculated from logarithmic phase cultures (i.e., WT and MnKat mutant) growing in either MRS or APT media without $\mathrm{H}_{2} \mathrm{O}_{2}$, to a starting $\mathrm{OD}_{600 \mathrm{~nm}}=0.08-0.09$.

Cultures were incubated aerobically at $37^{\circ} \mathrm{C}$ with continuous shaking, and changes in $\mathrm{OD}_{600 \mathrm{~nm}}$ were monitored as a function of time using the FLUOStar OPTIMA plate reader system (BMG LABTECH Inc., Durham, NC, USA). Data were plotted as a semi-log plot $\left(\mathrm{OD}_{600 \mathrm{~nm}}\right.$ vs. time), and maximum specific growth rate $\left(\mu_{\max } \cdot \mathrm{h}^{-1}\right)$ was calculated from the slope of the line during the exponential phase multiplied by 2.303. The specific growth rate replicates were averaged and fitted to a linear regression model, with SE bars based on small sample size standard deviation formula, using GraphPad Prism 4 for Macintosh (GraphPad Software, San Diego, CA, USA). Data represent the mean of at least two biological replicates. 


\subsection{Microscopy and Imaging}

Cultures were Gram-stained using standard bacteriological methods [34] and visualized with a Nikon Alphaphot Microscope (Nikon, Inc., Melville, NY, USA). Images were taken with a Nikon camera D40X SLR with $50 \mathrm{~mm}$ lens (Nikon, Inc. Melville, NY, USA).

\section{Results}

\subsection{NC1543 Is Devoid of Catalase (MnKat)}

Data in Figure 1 show that the mutant (NC1543) exhibited a complete absence of MnKat. Addition of $3 \% \mathrm{H}_{2} \mathrm{O}_{2}$ to cell smears of the mutant showed lack of effervescence whereas the isogenic wild-type strain (NC1542) displayed effervescence due to MnKat activity, Figure $1\{\mathrm{I}\}$. The lack of MnKat in L. plantarum (NC1543) was further confirmed by activity gel assay and Western-blot analysis, Figure $1\{\mathrm{II}$ and III $\}$, respectively activity, Figure 1\{I\}. The lack of MnKat in L. plantarum (NC1543) was further confirmed by activity gel assay and Western-blot analysis, Figure $1\{\mathrm{II}$ and III $\}$, respectively.

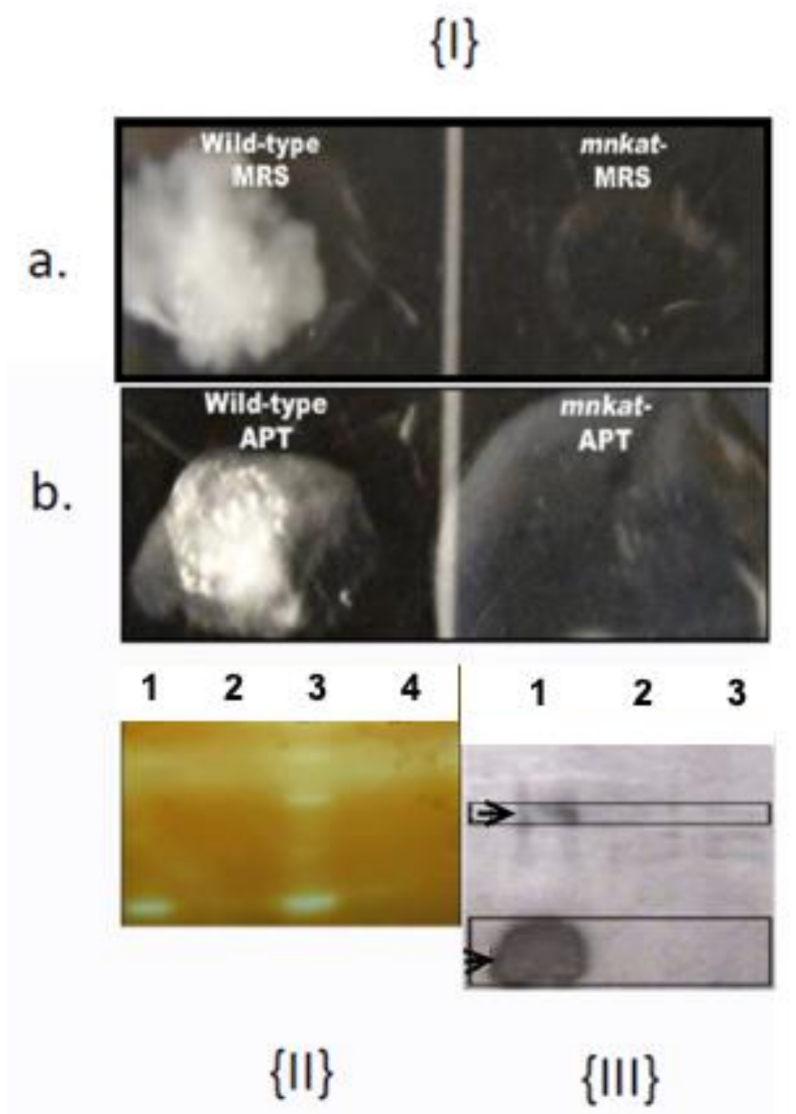

Figure 1. Biochemical properties of the MnKat mutant strain (NC1543) and its parental Wild type (NC1542). \{I\} Qualitative catalase activity-the test is based on the presence or absence of effervescence upon the addition of $3 \% \mathrm{H} 2 \mathrm{O} 2$ to a smear from a single colony. NC1542 and NC1543 were grown on MRS (a) or APT (b); $\{\mathbf{I I}\}$ Catalase activity gel-CFEs were prepared from cells grown in either MRS (Lanes 1 and 2) or APT (Lanes 3 and 4). Aliquots (50 $\mu \mathrm{g}$ protein per lane) were applied to $10 \%$ non-denaturing native PAGE gels, after electrophoresis the gels were stained for catalase using [32]. Achromatic bands seen in lanes 1 and 3, indicate the presence of active MnKat-Lanes 1 and 3 (NC1542); Lanes 2 and 4, (NC1543); \{III\} Western blotting of CFE's of NC1542 and NC1543separation of total proteins ( $5 \mu \mathrm{g} /$ lane) was performed using a 10\% denaturing SDS-PAGE. Following electroblotting, Mn-catalase was probed with Mn-catalase monoclonal antibodies, as described in $\mathrm{M}$ and M. Dark bands seen in lane 1 indicate the presence of MnKat antigens-Lane 1-wild-type grown in MRS, Lane 2-mutant grown in MRS, and Lane 3-mutant grown in APT. 
Furthermore, the specific activity of catalase in CFEs prepared from the WT strain (NC1542) and the mutant strain (NC1543) demonstrated that the mutant is devoid of MnKat, Figure 2. The specific activity of MnKat of the parent strain (NC1542) was 60\% higher in cells grown in APT as compared to cells grown in MRS media (i.e., $180.9 \pm 40.9$ vs. $112.9 \pm 0.9 \mathrm{U} / \mathrm{mg}$ protein), Figure 2 .

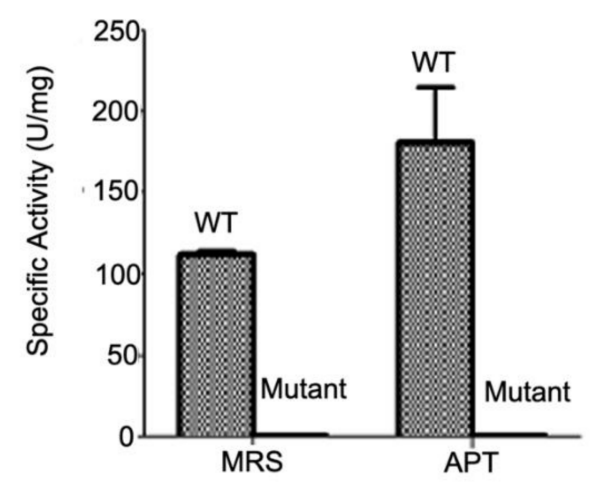

Figure 2. Catalase (MnKat) activity in L. plantarum (WT) NC1542 and (Mutant) NC1543. Cell-FreeExtracts were prepared from cells grown aerobically in MRS and APT Media. Standard error bars based on small sample size standard deviation using GraphPad prism 4 for Macintosh (GraphPad Software, San Diego, CA, USA). WT $112.9 \pm 0.9$ and $180.9 \pm 40.9 \mathrm{U} / \mathrm{mg}$ protein in MRS and APT, respectively; while the Mutant $00 \mathrm{U} / \mathrm{mg}$ protein in both media.

\subsection{MnKat and Cellular Physiology}

Gram-staining of cells grown on MRS, or APT media showed that the MnKat mutant and the wild-type strains were Gram-positive. However, the mutant and wild-type strain exhibited significant physiological differences.

\subsubsection{Effect of MnKat on Biochemical Profile}

The metabolic profile of mutant and wild-type strain was compared using API 20E ${ }^{\circledR}$ test strips under both aerobic and anaerobic conditions. The data showed that the biochemical patterns in both strains were identical; except that the mutant (NC1543) lacked catalase activity under both aerobic and anaerobic conditions and produced a lower concentration of acetoin (VP test) only under aerobic conditions (Table 1).

\subsubsection{Effect of MnKat on Sensitivity to $\mathrm{H}_{2} \mathrm{O}_{2}$}

The effects of $1 \mathrm{mM} \mathrm{H}_{2} \mathrm{O}_{2}$ on the growth kinetics of the mutant (NC1543) and the wildtype (NC1542) strains were examined using MRS and APT liquid media (Figure 3). Data showed that the specific growth rate $\left(\mu_{\max } \cdot \mathrm{h}^{-1}\right)$ of the wild-type strain in MRS, without $\mathrm{H}_{2} \mathrm{O}_{2}$, was 4-fold higher than that of the MnKat mutant strain (i.e., $0.76+/-0.025 \mathrm{~h}^{-1}$ vs. $0.19+/-0.05 \mathrm{~h}^{-1}$ ) (Figure $3 \mathrm{~A}$, MRS). However, with addition of $1 \mathrm{mM} \mathrm{H}_{2} \mathrm{O}_{2}$ to the MRS media, an approximate $\sim 15 \%$ reduction in the specific growth rate of wild-type strain (NC 1542) was observed compared to that seen in the absence of $\mathrm{H}_{2} \mathrm{O}_{2}\left(0.65+/-0.000 \mathrm{~h}^{-1}\right.$ vs. $\left.0.76+/-0.025 \mathrm{~h}^{-1}\right)$. The inclusion of $1 \mathrm{mM} \mathrm{H}_{2} \mathrm{O}_{2}$ completely inhibited growth of the mutant strain (NC 1543) (Figure 3B, MRS).

Conversely, growth of the wild-type in APT media, in the absence of $\mathrm{H}_{2} \mathrm{O}_{2}$, resulted in a slower specific growth rate than that observed in MRS (i.e., $0.58+/-0.001 \mathrm{~h}^{-1}$ vs. 0.76 $+/-0.025 \mathrm{~h}^{-1}$ ) (Figure 3A, APT vs. MRS). However, in APT media, the specific growth rate of the MnKat mutant strain (NC1543) was 2.8-fold higher than that in MRS (i.e., 0.54 $+/-0.01 \mathrm{~h}^{-1}$ vs. $\left.0.19+/-0.05 \mathrm{~h}^{-1}\right)$. Furthermore, addition of $1 \mathrm{mM} \mathrm{H}_{2} \mathrm{O}_{2}$ to APT media resulted in a comparable decrease $(\sim 22 \%)$ in the specific growth rate of the wild-type strain (NC1542) as was also observed in the MRS media (Figure 3A, APT vs. MRS). However, the specific growth rate of the MnKat mutant strain (NC1543) in the presence of $1 \mathrm{mM}$ 
$\mathrm{H}_{2} \mathrm{O}_{2}$ was greater in APT than in MRS media (i.e., $\mu_{\max }=0.25+/-0.05 \mathrm{~h}^{-1}$ vs. $0.00+/-$ $0.00 \mathrm{~h}^{-1}$ ) (Figure 3B, APT vs. MRS).

Table 1. Metabolic activities of wild-type (NC1542) and MnKat mutant (NC1543) as determined using API-20E. Cells used were grown statically in MRS under oxic or anoxic conditions.

\begin{tabular}{|c|c|c|c|c|c|}
\hline \multirow{2}{*}{ Tests $^{a}$} & \multirow{2}{*}{ Reactions/Enzymes } & \multicolumn{2}{|c|}{ Aerobic } & \multicolumn{2}{|c|}{ Anaerobic } \\
\hline & & WT & Mutant & WT & Mutant \\
\hline ONPG & $\beta$-galactosidase & - & - & - & - \\
\hline $\mathrm{ADH}$ & Arginine dehydrolase & - & - & - & - \\
\hline LDC & Lysine decarboxylase & - & - & - & - \\
\hline ODC & Ornithine decarboxylase & - & - & - & - \\
\hline CIT & Citrate utilization & - & - & - & - \\
\hline $\mathrm{H}_{2} \mathrm{~S}$ & Hydrogen Sulfide production & - & - & - & - \\
\hline URE & Urease & - & - & - & - \\
\hline TDA & Tryptophan deaminase & - & - & - & - \\
\hline IND & Indole & - & - & - & - \\
\hline $\mathrm{VP}$ & Vogues-Proskauer & + & weak $^{b}$ & + & + \\
\hline GEL & Gelatin liquefaction & - & - & - & - \\
\hline GLU & Glucose utilization & + & + & + & + \\
\hline MAN & Mannitol utilization & + & + & + & + \\
\hline INO & Inositol utilization & + & + & + & + \\
\hline SOR & Sorbitol utilization & + & + & + & + \\
\hline RHA & Rhamnose utilization & + & + & + & + \\
\hline SAC & Sucrose utilization & + & + & + & + \\
\hline MEL & Melibiose utilization & + & + & + & + \\
\hline AMY & Amygdalin utilization & + & + & + & + \\
\hline ARA & Arabinose utilization & + & + & + & + \\
\hline NIT RED & Nitrate reductase & + & + & + & + \\
\hline CAT & Catalase & $+^{\mathrm{C}}$ & - & + & $-\mathrm{d}$ \\
\hline OX & Oxidase & - & - & - & - \\
\hline
\end{tabular}

$\overline{\mathrm{a}}$ Acronyms for each reaction/enzyme; ${ }^{\mathrm{b}}$ Indicates a weak positive reaction intensity; ${ }^{\mathrm{c}}$ Indicates a positive reaction; and ${ }^{\mathrm{d}}$ Indicates a negative reaction.

\subsubsection{Effect of MnKat on Cell and Colony Morphology}

Cells of the mutant strain (NC1543), grown on MRS, appeared shorter and plumper compared to the more elongated and slender shaped cells of the wild-type strain (NC1542) grown under the same conditions (Figure $4 \mathrm{~A}$-upper images). The colonies of the mutant strain on MRS plates were round, pinpoint in size, slightly opaque, and exhibited a smooth surface compared to colonies of the wild-type strain that appeared round, opaque, and convex with an entire smooth glossy surface (Figure 4A-lower images). However, when cultivated on APT media, the cell morphology of the MnKat mutant (NC1543) appeared slightly shorter and plumper than the wild-type (Figure 4B-upper images); while the colonies of mutant strain were translucent, slightly raised, and irregular with a rough surface as opposed to those of the wild type (NC1542) that appeared round, opaque, and convex with an entire smooth glossy surface (Figure $4 \mathrm{~B}$-lower images). Interestingly, these morphological changes (i.e., colony and cellular) were not manifested when the mutant and wild-type strains were grown in MRS or APT under anaerobic conditions (data not shown). 

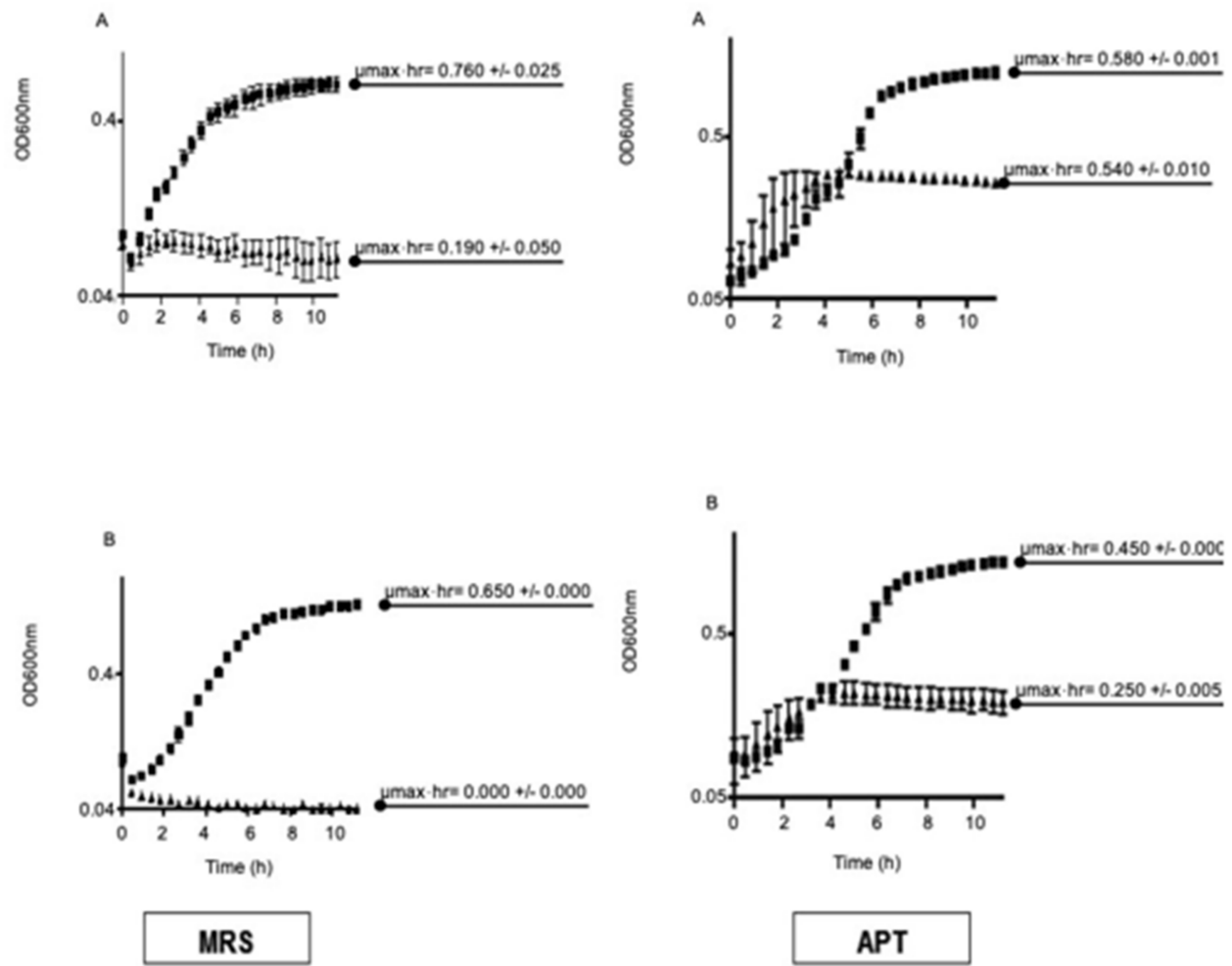

Figure 3. Growth kinetics of L. plantarum ATCC $14431(\boldsymbol{\square})$ and MnKat mutant ( $\mathbf{\Delta})$ strains in MRS and APT media in the presence and absence of $1 \mathrm{mM} \mathrm{H}_{2} \mathrm{O}_{2}$. Each point represents an average of biological duplicates and error bars represent SEM. (A) $0 \mathrm{mM} \mathrm{H}_{2} \mathrm{O}_{2}$; and (B) $1 \mathrm{mM} \mathrm{H}_{2} \mathrm{O}_{2}$.

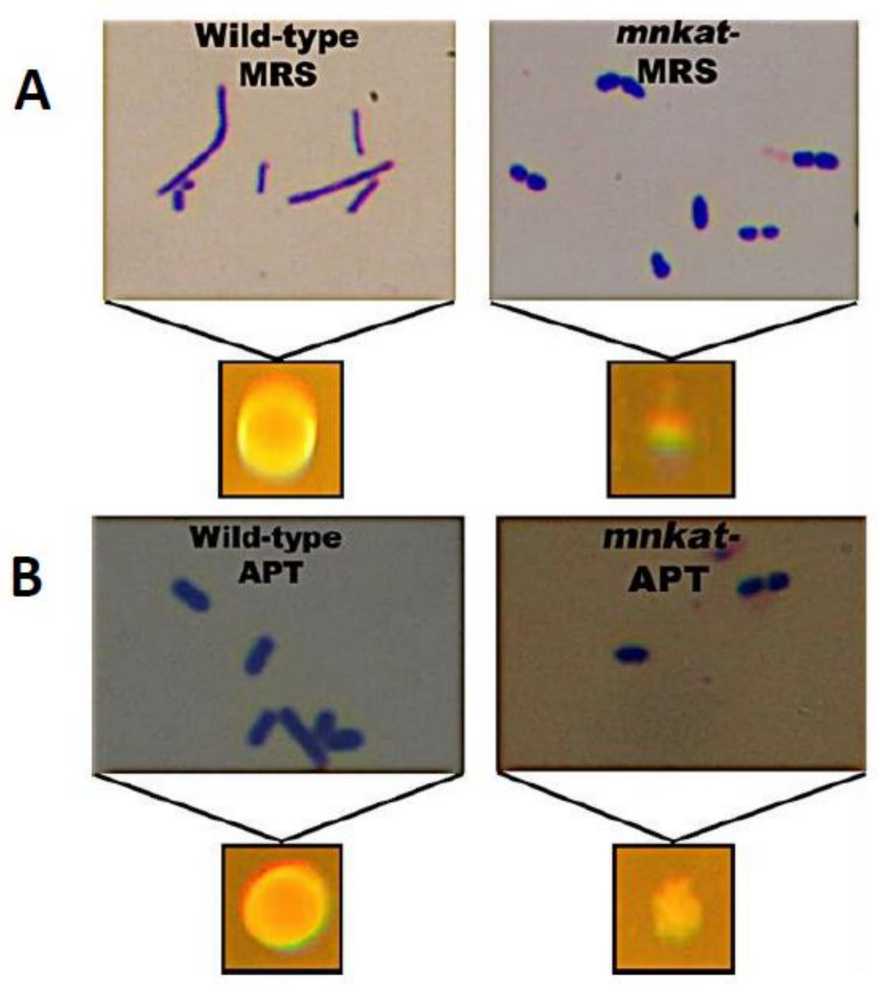

Figure 4. Gram-stain (top images) and colony morphology (lower images) of the wild-type L. plantarum NC1542 (left images) and its isogenic MnKat mutant strain NC 1543 (right images). (A) Cells grown on MRS; and (B) Cells grown on APT. 


\section{Discussion}

Lactobacilli are known to generate $\mathrm{O}_{2}{ }^{-}$and $\mathrm{H}_{2} \mathrm{O}_{2}$ and accumulate millimolar concentrations of the peroxide [1-6]. Mechanisms to combat the toxicity of ROS are essential for survival in presence of oxygen. Superoxide dismutases (SODs) and hydroperoxidases (i.e., catalases and peroxidases) provide the first line of defense against $\mathrm{O}_{2}{ }^{-}$and $\mathrm{H}_{2} \mathrm{O}_{2}$, respectively [35].

The presence of SODs in lactobacilli is sporadic. However, in the absence of SODs some lactobacilli accumulate high concentrations of intracellular manganese $(\sim 30 \mathrm{mM})[1,6,7,11]$. Lactic acid bacteria (LAB) are generally classified as catalase negative and incapable of synthesizing heme; however, heme-dependent catalases have been reported in some lactobacilli when an external source of heme is provided (23). The discovery of a non-heme catalase (MnKat) in L. plantarum led to several in-depth studies, including the cloning of the gene, determining the protein crystal structure, and characterizing enzyme properties [25-28]. The present report describes the use of a MnKat mutant to define the physiological function this enzyme plays in L. plantarum ATCC 14431 (NC1542).

Our data clearly supported the findings of Kono and Fridovich [29], who concluded that MnKat is important for $\mathrm{H}_{2} \mathrm{O}_{2}$ detoxification; however, the current findings also showed that in an oxygenated environment, the lack of MnKat had a profound effect on cellular morphology, metabolism, and growth kinetics. This conclusion was indicated by morphological changes (Figure $4 \mathrm{~A}, \mathrm{~B}$ ), and the ability to reverse those changes when the mutant strain (NC1543) was grown under anoxic conditions (data not shown).

Although differences in the specific growth rate $\left(k \cdot \mathrm{h}^{-1}\right)$ were observed when the wildtype strain (NC1542) was grown aerobically in MRS vs. APT media, in the presence and absence of exogenous $\mathrm{H}_{2} \mathrm{O}_{2}$ (Figure 3), the fold differences were similar (i.e., $~ 1.3$ and $~ 1.2$, respectively). The most profound variance was observed with the MnKat mutant strain (NC1543), where aerobic growth in MRS appeared to be hindered in both the presence and absence of exogenous $\mathrm{H}_{2} \mathrm{O}_{2}$ (Figure 3). However, when grown in APT medium, the mutant strain (NC1543) appeared to grow better even in the presence of exogenous $\mathrm{H}_{2} \mathrm{O}_{2}$ (Figure 3). Possibly components in the APT medium afforded some physiological benefit to these cells. Most likely this additional protective measure was due, in part, to the presence of higher concentrations of $\mathrm{MnCl}_{2}$ (i.e., $~ 3.2$ folds) in APT compared to MRS media. It is also interesting to note that, under aerobic conditions, the wild-type strain possessed $60 \%$ higher MnKat activity when grown in APT versus MRS media (i.e., 180 vs. $112 \mathrm{U} / \mathrm{mg}$ protein), probably due to the availability of higher [Mn], the enzyme's cofactor.

Furthermore, qualitative data (Table 1) showed that under aerobic conditions the wild-type strain NC1542 was positive in the Vogues-Proskauer test (VP), designates the production of acetoin/diacetyl, while the MnKat mutant strain NC1543 scored as weak. However, under anaerobic conditions both strains were equally VP-positive. The production of acetoin/diacetyl is dependent on the availability of pyruvate and the enzyme alpha-acetolactate synthase [36,37]. Thus, our data suggests that under aerobic conditions the presence of functional MnKat spares the availability of sufficient pyruvate to produce $\alpha$-acetolactate and acetoin/diacetyl. However, further studies are needed to prove the hypothesis.

Lastly, there are two important points to address regarding the function of MnKat under aerobic growth:

\subsection{How the Absence of the MnKat ENZYME CAUSES the Observed Changes in Cell Morphology?}

In the presence of oxygen, L. plantarum and other LAB generate millimolar concentrations of endogenous hydrogen peroxide [1-6]. In addition, L. plantarum ATCC 14431 possesses MnKat [25,27-30], but lacks superoxide dismutase (SOD) [7,11]. Consequently, the MnKat mutant (NC1543) is devoid of the enzymes required for the removal of both $\mathrm{O}_{2}{ }^{-}$and $\mathrm{H}_{2} \mathrm{O}_{2}$ (i.e., SODs and MnKat, respectively) and therefore most likely subject to increased exposure to ROS and experience oxidative stress [38]. 
It is also known that bacterial cell shapes are determined by the peptidoglycan (PG) layer of the cell wall, and unbalanced PG biosynthesis can cause changes in bacterial morphology [39-41]. Therefore, the data presented herein suggest that increased ROS in the MnKat mutant may result in unbalanced cell wall biosynthesis and triggers the observed changes in cell morphology. These changes can be reversed by the presence of MnKat or the absence of oxygen. Indeed, changes in cell morphology observed in the photosynthetic bacterium, Fremyella diplosiphon, during chromatic adaptation have been attributed to the generation of elevated ROS [42]. Also, morphological changes within bacteria and LAB have been documented as natural events [24], stress induced events [43,44], or genetic events [45]. Currently, the exact molecular mechanism of how increased ROS affect cell wall biosynthesis and cell morphology is unknown, and further research is needed.

\subsection{How can Manganese Protect against Hydrogen Peroxide Toxicity?}

In general, manganese is an essential micronutrient for living cells. It is important for the catalytic activity of many antioxidant enzymes (e.g., MnSOD, MnKat, etc.), many metabolic enzymes (e.g., those involved with carbohydrate, amino acid processing, etc.), and gene regulation [46-50]. It was previously shown that $L$. plantarum possesses manganese transport systems [51-53], and intracellular Mn was sequestered via high molecular weight protein-polyphosphate molecules [11,54]. It was also demonstrated that limiting the concentration of phosphate reduces the uptake of $\mathrm{Mn}(\mathrm{II})$, which, in turn, increased $L$. plantarum sensitivity to ROS $[7,11,54]$. In addition, Mn-complexes (i.e., Mn-pyrophosphates and Mn-polyphoshates) were shown to protect against oxidative damage caused by hydroxyl radical ( $\mathrm{HO} \bullet$ ) generated from $\mathrm{H}_{2} \mathrm{O}_{2}$ and iron under aerobic conditions [55]. Given the chemistry involved in the generation of $\mathrm{HO} \bullet$ from $\mathrm{H}_{2} \mathrm{O}_{2}$ via "Fenton" or "Haber-Weiss" reactions, a likely scenario for the role of Mn in protecting the MnKat mutant of L. plantarum against the toxicity of hydrogen peroxide might be proposed.

\section{Conclusions}

- Under aerobic conditions, MnKat is essential for normal aerobic growth of L. plantarum ATCC 14431; it is required for removing endogenous $\mathrm{H} 2 \mathrm{O} 2$;

- Inactivation of MnKat results in hyper-sensitivity to added H2O2; and

- Media containing high Mn concentrations (e.g., APT) improves the growth of the MnKat mutant strain (NC1543) relative to that seen in the low Mn medium (e.g., MRS).

- This information will help to guide future investigations into alternative mechanisms for ROS detoxification and broaden studies on the role of Mn-catalases in other members of the LAB group as well as other prokaryotes. The findings will also bring awareness of the need to protect economically important organisms (e.g., LAB and probiotics) against oxidative stress, which is very important in the food fermentation and microbiome studies.

Author Contributions: Conceptualization, H.M.H.; methodology, T.P. and H.M.H.; software, T.P.; validation, H.M.H. and T.P.; formal analysis, T.P.; investigation, T.P.; resources, H.M.H.; data curation, T.P.; writing—original draft preparation, T.P.; writing—review and editing, H.M.H.; visualization, H.M.H. and T.P.; supervision, H.M.H.; project administration, H.M.H.; funding acquisition, H.M.H. All authors have read and agreed to the published version of the manuscript.

Funding: This work was supported by funds from the North Carolina Agricultural Research Services. Institutional Review Board Statement: Not applicable.

Informed Consent Statement: Not applicable.

Data Availability Statement: All data are contained within the manuscript. Any inquiry should be sent to the corresponding author or the coauther. 
Acknowledgments: Thanks to J. W. Whittaker for providing monoclonal antibodies to Mn-catalase and to Nivien Abdel Rahman for her technical expertise during these studies. Special thanks to Debra Clare for critically reading the manuscript.

Conflicts of Interest: The authors declare no conflict of interest.

\section{References}

1. Archibald, F.S. Manganese: Its Acquistion by and Function in the Lactic Acid Bacteria. CRC Crit. Rev. Microbiol. 1986, 13, 63-109. [CrossRef]

2. Condon, S. Responses of lactic acid bacteria to oxygen. FEMS Microbiol. Rev. 1987, 46, 269-280. [CrossRef]

3. Gotz, F.; Sedewitz, B.; Elstner, E.F. Oxygen utilization by Lactobacillus plantarum. I. Oxygen consuming reactions. Arch. Microbiol. 1980, 125, 209-214. [CrossRef]

4. Murphy, M.G.; Condon, S. Correlation of oxygen utilization and hydrogen peroxide accumulation with oxygen induced enzymes in Lactobacillus plantarum cultures. Arch. Microbiol. 1984, 138, 44-48. [CrossRef]

5. Teusink, B.; van Enckevort, F.H.; Francke, C.; Wiersma, A.; Wegkamp, A.; Smid, E.J.; Siezen, R.J. In silico reconstruction of the metabolic pathways of Lactobacillus plantarum: Comparing predictions of nutrient requirements with those from growth experiments. Appl. Environ. Microbiol. 2005, 71, 7253-7262. [CrossRef]

6. Archibald, F.S.; Duong, M.N. Manganese acquisition by Lactobacillus plantarum. J. Bacteriol. 1984, 158, 1-8. [CrossRef]

7. Archibald, F.S.; Fridovich, I. Manganese and defenses against oxygen toxicity in Lactobacillus plantarum. J. Bacteriol. 1981, 145, 442-451. [CrossRef]

8. Abriouel, H.; Herrmann, A.; Starke, J.; Yousif, N.M.; Wijaya, A.; Tauscher, B.; Holzapfel, W.; Franz, M. Cloning and heterologous expression of hematin-dependent catalase produced by Lactobacillus plantarum CNRZ 1228. Appl. Environ. Microbiol. 2004, 70, 603-606. [CrossRef]

9. Amanatidou, A.; Smid, E.J.; Bennik, M.H.; Gorris, L.G. Antioxidative properties of Lactobacillus sake upon exposure to elevated oxygen concentrations. FEMS Microbiol. Lett. 2001, 203, 87-94. [CrossRef] [PubMed]

10. Andrus, J.M.; Bowen, S.W.; Klaenhammer, T.R.; Hassan, H.M. Molecular characterization and functional analysis of the manganese-containing superoxide dismutase gene (sodA) from Streptococcus thermophilus AO54. Arch. Biochem. Biophys. 2003, 420, 103-113. [CrossRef] [PubMed]

11. Archibald, F.S.; Fridovich, I. Manganese, superoxide dismutase, and oxygen tolerance in some lactic acid bacteria. J. Bacteriol. 1981, 146, 928-936. [CrossRef]

12. Dacre, J.C.; Sharpe, M.E. Catalase production by Lactobacilli. Nature 1956, 178, 700. [CrossRef]

13. De Angelis, M.; Gobbetti, M. Lactobacillus sanfranciscensis CB1: Manganese, oxygen, superoxide dismutase and metabolism. Appl. Microbiol. Biotechnol. 1999, 51, 358-363. [CrossRef] [PubMed]

14. Hertel, C.; Schmidt, G.; Fischer, M.; Oellers, K.; Hammes, W.P. Oxygen-dependent regulation of the expression of the catalase gene katA of Lactobacillus sakei LTH677. Appl. Environ. Microbiol. 1998, 64, 1359-1365. [CrossRef] [PubMed]

15. Johnston, M.A.; Delwiche, E.A. Distribution and Characteristics of the catalases of Lactobacilliacaea. J. Bacteriol. 1965, 90, 347-351. [CrossRef] [PubMed]

16. Johnston, M.A.; Delwiche, E.A. Isolation and Characterization of the cyanide-resistant and azide-resistant catalase of Lactobacillus plantarum. J. Bacteriol. 1965, 90, 352-356. [CrossRef]

17. Knauf, H.J.; Vogel, R.F.; Hammes, W.P. Cloning, sequence, and phenotypic expression of katA, which encodes the catalase of Lactobacillus sake LTH677. Appl. Environ. Microbiol. 1992, 58, 832-839. [CrossRef] [PubMed]

18. Kono, Y.; Fridovich, I. Isolation and characterization of the pseudocatalase of Lactobacillus plantarum. J. Biol. Chem. 1983, 258, 6015-6019, Accession Number: 6853475. [CrossRef]

19. Kullisaar, T.; Zilmer, M.; Mikelsaar, M.; Vihalemm, T.; Annuk, H.; Kairane, C.; Kilk, A. Two antioxidative lactobacilli strains as promising probiotics. Int. J. Food Microbiol. 2002, 72, 215-224. [CrossRef]

20. Noonpakdee, W.; Sitthimonchai, S.; Panyim, S.; Lertsiri, S. Expression of the catalase gene katA in starter culture Lactobacillus plantarum TISTR850 tolerates oxidative stress and reduces lipid oxidation in fermented meat product. Int. J. Food Microbiol. 2004, 95, 127-135. [CrossRef]

21. Poyart, C.; Berche, P.; Trieu-Cuot, P. Characterization of superoxide dismutase genes from gram-positive bacteria by polymerase chain reaction using degenerate primers. FEMS Microbiol. Lett. 1995, 131, 41-45. [CrossRef]

22. Sanders, J.W.; Leenhouts, K.J.A.; Haandrikman, J.; Venema, G.; Kok, J. Stress response in Lactococcus lactis: Cloning, expression analysis, and mutation of the lactococcal superoxide dismutase gene. J. Bacteriol. 1995, 177, 5254-5260. [CrossRef] [PubMed]

23. Wolf, G.; Strahl, A.; Meisel, J.; Hammes, W.P. Heme-dependent catalase activity of lactobacilli. Int. J. Food Microbiol. 1991, 12, 133-140. [CrossRef]

24. Hammes, W.P.; Hertel, C. The Genera Lactobacillus and Carnobacterium. Prokaryotes 2006, 4, 320-403.

25. Igarashi, T.; Kono, Y.; Tanaka, K. Molecular cloning of manganese catalase from Lactobacillus plantarum. J. Biol. Chem. 1996, 271, 29521-29524. [CrossRef]

26. Rochat, T.; Gratadoux, J.J.; Gruss, A.; Corthier, G.; Maguin, E.; Langella, P.; van de Guchte, M. Production of a heterologous nonheme catalase by Lactobacillus casei: An efficient tool for removal of $\mathrm{H}_{2} \mathrm{O}_{2}$ and protection of Lactobacillus bulgaricus from oxidative stress in milk. Appl. Environ. Microbiol. 2006, 72, 5143-5149. [CrossRef] 
27. Barynin, V.V.; Whittaker, M.M.; Antonyuk, S.V.; Lamzin, V.S.; Harrison, P.M.; Artymiuk, P.J.; Whittaker, J.W. Crystal structure of manganese catalase from Lactobacillus plantarum. Structure 2001, 9, 725-738. [CrossRef]

28. Whittaker, M.M.; Barynin, V.V.; Igarashi, T.; Whittaker, J.W. Outer sphere mutagenesis of Lactobacillus plantarum manganese catalase disrupts the cluster core: Mechanistic implications. Eur. J. Biochem. 2003, 270, 1102-1116. [CrossRef]

29. Kono, Y.; Fridovich, I. Functional significance of manganese catalase in Lactobacillus plantarum. J. Bacteriol. 1983, 155, 742-746. [CrossRef]

30. Peacock, T.J. Biological role of Mn-catalase in select Lactobacilli. Ph.D. Thesis, North Carolina State Unviersity, Raleigh, NC, USA, 2008. Available online: http:/ / www.lib.ncsu.edu/resolver/1840.16/4007 (accessed on 10 June 2021).

31. Bradford, M.M. A rapid and sensitive method for the quantitation of microgram quantities of protein utilizing the principle of protein-dye binding. Anal. Biochem. 1976, 72, 248-254. [CrossRef]

32. Clare, D.A.; Duong, M.N.; Darr, D.; Archibald, F.; Fridovich, I. Effects of molecular oxygen on detection of superoxide radical with nitroblue tetrazolium and on activity stains for catalase. Anal. Biochem. 1984, 140, 532-537. [CrossRef]

33. Beers, R.F.J.; Sizer, I.W. A spectrophotometric method for measuring the breakdown of hydrogen peroxide by catalase. J. Biol. Chem. 1952, 195, 133-140, Accession Number: 14938361. [CrossRef]

34. Claus, G.W. Understanding Microbes: A Laboratory Textbook for Microbiology; W.H. Freeman \& Co.: New York, NY, USA, 1989.

35. Hassan, H.M. Oxygen toxicity and mutagenicity in procaryotes. In Oxy Radicals and their Schavengers Systems; Molecular Aspects. Cohen, G., Greenwald, R., Eds.; Elsevier: Amsterdam, The Netherlands, 1983; Volume 1, pp. 198-206.

36. Zuljan, F.A.; Repizo, G.D.; Alarcon, S.H.; Magni, C. $\alpha$-Acetolactate synthase of Lactococcus lactis contributes to pH homeostasis in acid stress conditions. Int. J. Food Microbiol. 2014, 188, 99-107. [CrossRef]

37. Liu, S. A Simple method to generate chromosomal mutations in Lactobacillus plantarum strain TF103 to eliminate undesired fermentation products. Appl. Biochem. Biotechnol. 2006, 131, 854-863. [CrossRef]

38. Schellhorn, H.; Hassan, H.M. Response of hydroperoxidase and superoxide dismutase deficient mutants of Escherichia coli to oxidative stress. Can. J. Microbiol. 1988, 34, 1171-1176. [CrossRef]

39. Pérez-Núňez, D.; Briandet, R.; David, B.; Gautier, C.; Renault, P.; Hallet, B.; Hols, P.; Carballido-López, R.; Guédon, E. A new morphogenesis pathway in bacteria: Unbalanced activity of cell wall synthesis machineries leads to coccus-to-rod transition and filamentation in ovococci. Mol. Microbiol. 2011, 79, 759-771. [CrossRef]

40. Bendezu, F.O.; de Boer, P.A. Conditional lethality, division defects, membrane involution, and endocytosis in mre and $m r d$ shape mutants of Escherichia coli. J. Bacteriol. 2008, 190, 1792-1811. [CrossRef]

41. Den Blaauwen, T.; de Pedro, M.A.; Nguyen-Disteche, M.; Ayala, J.A. Morphogenesis of rod-shaped sacculi. FEMS Microbiol. Rev. 2008, 32, 321-344. [CrossRef] [PubMed]

42. Singh, S.P.; Montgomery, B.L. Reactive oxygen species are involved in the morphology-determining mechanism of Fremyella diplosiphon cells during complementary chromatic adaptation. Microbiology 2012, 158, 2235-2245. [CrossRef]

43. Molina-Hoppner, A.; Sato, T.; Kato, C.; Ganzle, M.G.; Vogel, R.F. Effects of pressure on cell morphology and cell division of lactic acid bacteria. Extremophiles 2003, 7, 511-516. [CrossRef]

44. Thibessard, A.; Fernandez, A.; Gintz, B.; Leblond-Bourget, N.; Decaris, B. Effects of rodA and $p b p 2 b$ disruption on cell morphology and oxidative stress response of Streptococcus thermophiles CNRZ368. J. Bacteriol. 2002, 184, 2821-2826. [CrossRef]

45. Jankovic, I.; Ventura, M.; Meylan, V.; Rouvet, M.; Elli, M.; Zink, R. Contribution of aggregation-promoting factor to maintenance of cell shape in Lactobacillus gasseri 4B2. J. Bacteriol. 2003, 185, 3288-3296. [CrossRef]

46. Macleod, R.A.; Snell, E.E. Some mineral requirements of the lactic acid bacteria. J. Biol. Chem. 1947, 170, 351-365. [CrossRef]

47. Nierop Groot, M.N.; de Bont, J.A. Involvement of manganese in conversion of phenylalanine to benzaldehyde by lactic acid bacteria. Appl. Environ. Microbiol. 1999, 65, 5590-5593. [CrossRef]

48. Nierop Groot, M.N.; de Bont, J.A.M. Conversion of phenylalanine to benzaldehyde initiated by an aminotransferase in Lactobacillus plantarum. Appl. Environ. Microbiol. 1998, 64, 3009-3013. [CrossRef]

49. Raccach, M.; Marshall, P.S. Effect of manganese ions on the fermentative activity of frozen-thawed lactobacilli. J. Food Sci. 1985, 50, 665-668. [CrossRef]

50. Stetter, K.O.; Zillig, W. Transcription in lactobacillaceae. DNA-dependent RNA polymerase from Lactobacillus curvatus. Eur. J. Biochem. 1974, 48, 527-540. [CrossRef] [PubMed]

51. Groot, M.N.; Klaassens, E.; de Vos, W.M.; Delcour, J.; Hols, P.; Kleerebezem, M. Genome-based in silico detection of putative manganese transport systems in Lactobacillus plantarum and their genetic analysis. Microbiology 2005, 151, 1229-1238. [CrossRef] [PubMed]

52. Hao, Z.; Chen, S.; Wilson, D.B. Cloning, expression, and characterization of cadmium and manganese uptake genes from Lactobacillus plantarum. Appl. Environ. Microbiol. 1999, 65, 4746-4752. [CrossRef] [PubMed]

53. Hao, Z.; Reiske, H.R.; Wilson, D.B. Characterization of cadmium uptake in Lactobacillus plantarum and isolation of cadmium and manganese uptake mutants. Appl. Environ. Microbiol. 1999, 65, 4741-4745. [CrossRef] [PubMed]

54. Archibald, F.S.; Fridovich, I. Investigations of the state of manganese in Lactobacillus plantarum. Arch. Biochem. Biophys. 1982, 215, 589-596. [CrossRef]

55. Cheton, P.L.; Archibald, F.S. Manganese complexes and the generation and scavenging of hydroxyl free radicals. Free. Rad. Biol. Med. 1988, 5, 325-333. [CrossRef] 